\title{
EXILIO-DISCURSO, PRÓTESIS INFRAHISTÓRICA Y MEMORIA absoluta en Monarca de Raúl Barrientos*
}

\author{
Dr. Marcelo Garrido Monroy**
}

\section{Resumen}

Monarca (1997) es el trabajo de una doble no pertenencia. Este carácter disfuncional es la expresión de una subjetividad anómala que intenta resolver una situación de irregularidad mediante un exilio-discurso. El espacio del exilio le niega a este sujeto la inclusión en una escena histórica, razón por la cual produce "prótesis infrahistóricas" mediante una serie fragmentos narrativos, protagonizados por subjetividades intemporales y derrotadas, discurso de carácter coral que genera una memoria absoluta.

Palabras claves: Monarca, exilio, historia, memoria.

\section{EXILE-SPEECH, INFRA-HISTORICAL PROSTHESIS AND ABSOlUTE MEMORY IN MONARCA OF RAÚl BARRIENTOS}

\begin{abstract}
Monarca (1997) is the fruit of a double non-ownership. This disfunctional character is the expression of an anomalous subjectivity that tries to solve a situation of irregularity by means of an exile-speech. The space of the exile denies the inclusion in a historical scene to this subject, therefore it produces infra-historical prosthesis by a series of narrative passages which are played by untemporal subjectivities and defeated entities. In Monarca, the writing endeavour elaborates an expression that is particularized in a speech of choral character, generating a sort of absolute memory.
\end{abstract}

Keywords: monarch, exile, history, memory.

Recibido: 31-07-2014

Aceptado: 15-10-2015

* Este artículo ha sido redactado a partir del capítulo: “Agenciamiento y prótesis infrahistórica en la poética de Raúl Barrientos: Monarca (1997)" incluido en la tesis para optar al grado de Magister en Literaturas Hispánicas de la Universidad de Concepción: Dos poéticas marcadas por la presencia del exilio (Enrique Lihn, Raúl Barrientos) del año 2005, guiada por la Profesora María Nieves Alonso M.

* Doctor en Literatura Latinoamericana por la Universidad de Concepción. Académico e investigador especializado en el ámbitos de la poesía chilena, Universidad Católica de Temuco, Temuco, Chile. mgarrido@uct.cl 


\section{Introducción:}

\section{"Yo soy el que vuela y usted la monarca"}

Hay una serie de expresiones crítico-teóricas que intentan dar cuenta de la naturaleza creativa de la literatura chilena del exilio. Ciertamente, estas se articulan en zonas de experiencia, incluso anteriores al golpe de estado; espacios de realidad que se extienden hasta fines de siglo y parecen definidos por un mismo referente multiforme: la violencia económica y sus complejas articulaciones políticas. En esa territorialidad concreta fue posible discutir y participar de un diálogo crispado entre fuerzas sociales que se reconocen en su diferencia ideológica, vale decir, en su diferencia moderna. En este sentido, el exilio constituyó una más de las articulaciones de esta tensión y se pensó entonces en ese marco acotado. A partir de lo que se ha denominado el fin de la modernidad, esto ya no es posible, pues esta clausura arrastra consigo los sueños del arraigo que muy en el fondo -y a pesar de los programas ideológicos declarados-cultivaron los socialismos y nacionalismo latinoamericanos a partir, nos parece, de las décadas de los 30 y 40 . Hay que definir un nuevo marco para esta discusión, pues no se trató de destierros particulares o de grupos intelectualmente preparados para la teorización y el liderazgo; así como los exterminios y las desapariciones, el exilio fue masivo. En este contexto de racionalismo radicalizado, el exilio así definido se transforma en una condición para la subjetividad, pues le quita a la experiencia del extrañamiento la garantía de singularidad, fundamental en la tradición anterior.

Resulta paradójico que, de forma paralela a la diferencia cultural, definida por las antiguas formas de la permanencia y el arraigo, se constituya de forma más o menos sistemática una cultura del desarraigo, sostenida por el trabajo riguroso y cruel de los dispositivos del mercado internacional. Paradójico pues, fascinados por el espejismo moderno y sus articulaciones utópicas, se ha favorecido de forma brutal el desarraigo, se ha trabajado en una suerte de exilio por venir, el que finalmente ha establecido su naturaleza. Sobre esta ruina de la identidad, a la que ha contribuido el colapso ideológico, se ha revelado un nuevo tipo de absurdo muy parecido a la nostalgia.

La obra poética de Raúl Barrientos (Puerto Montt, 1942-2012) gira en su totalidad sobre este eje paradójico del exilio. En las páginas que 
siguen nos abocamos al estudio de su libro Monarca (1997). Este libro fue publicado por Ediciones Cordillera, sello editorial creado por artistas chilenos exiliados en Otawa, Canadá. Como se indica en el interior del texto, gran parte de los poemas fue premiado en 1993 por el Consejo Nacional del Libro y la Lectura, lo que da cuenta de la relación que el autor mantiene con la tradición literaria del país y su institucionalidad cultural. A pesar del hecho de que la materia de los textos es el fruto de su largo exilio norteamericano, específicamente en la ciudad de Nueva York, la totalidad de su obra se escribió en español y se conecta por una serie de signos con la tradición poética chilena, inscribiéndose -nos parecesignificativamente en ella. Barrientos ha publicado Ese mismo sol (1981), Histórica relación del reyno de la noche (1982), Pie del Efímero (1985), Libro de las imágenes (1989), Monarca (1997), El balsero de Cucao (2000).

En trabajos anteriores hemos señalado que la poesía de Raúl Barrientos es el trabajo de una doble no pertenencia. En el presente artículo me propongo demostrar, principalmente, que este carácter disfuncional es la expresión de una subjetividad anómala que intenta resolver una situación de irregularidad mediante un exilio-discurso. Así también, y como resultado de esta articulación creativo-discursiva-disfuncional, nos interesa explorar dos aspectos de esta poética: la producción de prótesis infrahistóricas mediante una serie fragmentos narrativos protagonizados por subjetividades intemporales y entes derrotados y, por último, la creación de una memoria absoluta.

Monarca posee en portada, bajo el título y dispuesta de forma diagonal-ascendente, la imagen de una mariposa. El enunciado monarca -que cuelga sobre la imagen- alude al insecto representado, es decir a la mariposa monarca (Danaus plexippus) ${ }^{1}$.

La representación recuerda o sugiere la forma en que son presentados los invertebrados en los insectarios, fijados por medio de un alfiler y señalados por una etiqueta con su denominación popular y científica.

1 Este invertebrado posee cualidades singulares que en nuestro análisis resultan importantes: "Esta preciosa mariposa anaranjada, negra y blanca habita en América del Norte. Come plantas tóxicas que la hacen venenosa y repugnante. Al contrario que otras mariposas, no intenta ocultar sus brillantes colores porque éstos advierten de que es venenosa. Todos los otoños emigran más de $3.000 \mathrm{~km}$, desde Canadá y el norte de los Estados Unidos hasta Florida, México o California, donde pasan el invierno. Todos los años realizan la misma ruta, descansan en los mismos sitios y se dirigen al mismo árbol. Durante la semi-hibernación invernal, decenas de miles de estos lepidópteros comparten el mismo árbol." Enciclopedia Microsoft ${ }^{\circledR}$ Encarta® 2002. (C) 1993-2001 Microsoft Corporation. Reservados todos los derechos. 
Sin embargo, la cifra será significativa en la medida que se advierta la relación entre el enunciado "monarca" y la imagen de la mariposa. Es decir, hay un elemento oculto, la palabra "mariposa", asunto que dificulta la relación. La palabra "mariposa" no aparece, el dato que remplaza la ausencia es una imagen, la imagen de una mariposa. Lo cierto es que la palabra "monarca" no nombra la condición de un sujeto específico, de un gobernante, no hay determinante para el sustantivo, no hay $e l, l a$, un o una; en su lugar, hay una imagen y aquí el término imagen aparece en su significación literal, la imagen de una mariposa. Tendríamos que decir entonces que la palabra "monarca" aparece determinada por la imagen de una mariposa, asediada por la imagen de una mariposa que se precipita sobre la palabra desnuda. Pero también, tendríamos que decir que la palabra "monarca" tiene un valor adjetivo, si pensamos que la imagen es la sustancia determinada, de lo cual se extraería el enunciado siguiente: "mariposa monarca" 2 . Esta segunda lectura de la portada es, si se quiere, más directa, mientras que la primera moviliza de forma crítica otros elementos relacionados con la representación y los procedimientos representacionales de elementos sígnicos diversos: una imagen y una palabra. Queremos decir, en último caso, que en portada se presenta una suerte de diálogo entre la imagen y la palabra, en donde la primera problematiza críticamente a la segunda.

El verso de Vicente Huidobro que introduce el texto: "He ahí el destino de la mariposa magnética" (Monarca 9), establece la problemática fundamental que en adelante intentará resolver la escritura. Es una huella que señala el centro del texto. Desde el lenguaje se señala la condición de la "mariposa", su destino, que consiste en la atracción. Pero esta insinuación está incompleta. No sabemos si la mariposa es atraída, atraída y negligente (Foucault, El pensamiento... 33-41), o si es el punto de atracción, el lugar, el espacio que encarna la posibilidad del viaje. La mariposa es el lugar -“He ahí"- de su "destino". Tiene el atributo del magnetismo, está definida en función de un atributo, de un afecto: es la "mariposa magnética". Por lo tanto, este verso creacionista es también una pregunta que asedia la ley de las atracciones. Y en este sentido, el

2 Sólo un conocedor de insectos o un habitante más o menos informado del territorio que comprende desde Canadá y el norte de los Estados Unidos hasta Florida, México o California está en condiciones de descifrar la relación, puesto que la mariposa monarca cubre este extenso territorio en el viaje más largo registrado en el mundo de los insectos. 
texto vendría a responder o bien a transfigurar radicalizando ese destino, pero agenciando con él. La escritura de Monarca, al devenir mariposa, encarna un destino que se define por una condición específica: la del vuelo, la del viaje. Pero no cualquier vuelo, no cualquier viaje. Dicho vuelo tiene un punto de atracción o, incluso, la ilusión de un punto; una imagen que exige a la mariposa, que hace de su vuelo un vuelo delirante: "mariposa magnética", que al atraer es atraída. Este punto de atracción podría ser Chile, como también, el espacio sobrecodificado de la urbe norteamericana. Pero es la imagen, sólo la imagen, el espectro de lo que se ha perdido y que al perderse aparece en el sin lugar del exilio experimentado como destino, como un espacio de delirio continuo.

El poema que abre el texto resulta clarificador respecto de lo que avisa la portada y el epígrafe. "Yo soy el que vuela y usted la monarca" es un poema umbral, puesto que a través de él se accede a las diversas problemáticas que el texto moviliza, cifra el encuentro entre la problemática del sujeto exiliado y la intención de radicalizar la condición del exilio, profundizando en su significado. El poema nos habla de un agenciamiento, traza un desplazamiento en el cual los atributos de la mariposa pasan a formar parte de la esencialidad del sujeto. A su vez, la mariposa cobra en el atributo escritural del mismo sujeto una voz fragmentaria. Lo anterior viene a desestructurar la realidad percibida: una suma de fragmentos que -en su indiferencia- completan la fábula defectuosa de Occidente, el allá de la memoria y el aquí de los callejones herrumbrosos de la megalópolis norteamericana. Esto último determina el eje que en adelante configurará el espacio escritural. Lo que se actualiza en el enunciado -“Yo soy el que vuela y usted la monarca” - es la presencia de un aparato escritural de tipo maquínico, señalado en los postulados deleuzianos: un agenciamiento entre el sujeto precario de la expresión y la mariposa monarca. Lo que comparten, lo que se ceden mutuamente en pos de un mismo esfuerzo representacional es, por una parte, la posibilidad discursivo-precaria del sujeto y, por otra, el vuelo de la mariposa, la posibilidad intensa del movimiento migratorio.

Una característica de los poemas que forman el libro es la incorporación de un dispositivo narrativo. Una maquinaria narrativa domina la textualidad, generando un híbrido poético-narrativo. El primer poema se abre con un guion, utilizado en narrativa para introducir el discurso de un personaje: "-Y otros veranos llovía (...)" (11). Mediante 
este procedimiento se introduce el discurso de la monarca o la puesta en escena narrativo-poética de la subjetividad alterna o en diálogo. Para diferenciar este flujo de subjetividad se utiliza la cursiva.

La disposición de aparatos narrativos también determina un flujo de escritura más o menos conversacional o coloquial, si se quiere. Esto autoriza la aparición de ciertos tópicos, propios del espacio discursivo cotidiano, es decir, muletillas, frases hechas, refranes rearticulados, elementos fáticos y apelativos, etc. Estos mismos aparatos narrativos exigen el uso del versículo y no del verso. Es decir, el ritmo del (y los) poema(s) corresponde al de una narración, las ideas se articulan según una estructura que actualiza pequeños segmentos narrativos. La textualidad oscila entre una narratividad fragmentaria y una poética de delirio que desarticula constantemente el progreso de la historia. La estructura narrativa, que exige una ruta lógica, es quebrada insistentemente por el flujo poético. Este ritmo quebrado viene a ser el del vuelo de la mariposa, cuyo vuelo desordenado, pero al mismo tiempo obstinado, domina el texto.

Es por esto que, en último caso, no hay ni narrativa ni poética, sino un espacio literario transfigurado, una lengua en delirio, una punta de desterritorialización que se mueve de forma impensada por el sin-lugar del exilio. Este primer poema avisa un estado de agenciamiento que se produce por una afectación mutua entre la subjetividad básica del texto y la mariposa. Dicha afectación, a su vez, es posible por el encuentro entre ambos "animales" en el recinto que sustrae la escritura a la realidad. Este espacio de la transfiguración y de la contradicción es el topos indiferente del exilio. Ambos, mariposa y sujeto, son movidos por sendos procesos. La mariposa, por una parte, retenida en la habitación, exiliada del viaje migratorio, exiliada de su exilio vital deviene barro, se transfigura en voz y su fuga anómala arrastra al sujeto que se representa en ella. Por otra parte, dicho sujeto se incluye, por una necesidad de agenciamiento, en el destino de la mariposa. Podría afirmarse que el sujeto se ve a sí mismo en la mariposa. Se ve a sí mismo, puesto que la mariposa lo recoge en su discurso:

Con el naipe en el puño nos dejamos llevar por la lluvia, de pie sobre un territorio de certezas en que nunca

Se confundiría el rayo de julio con la sequía de enero, nunca jamás el ámbar con la muerte. (11) 
El saber del exilio es un espacio contradictorio, puesto que sobre la pantalla de un conocimiento actual y directo se proyecta, como una fantasmagoría, el conocimiento original. Y es evidente que ya no se trata de definir cuál es la realidad, sino más bien asumir que la realidad es ese encuentro impensado. Enero es el mes del verano y julio el mes de las lluvias en el hemisferio sur. Lo contrario ocurre en el hemisferio norte. Esta simple aseveración escolar está problematizada por el enunciado contradictorio "Y otros veranos llovía..." (11), enunciado que es posible en un tipo de realidad otro, en un tipo otro de saber que es propio de la condición específica del exilio. No hay confusión posible, no se trata de un error en la percepción, lo que se experimenta no es la pérdida, sino la experiencia. Por ello, la mariposa atrapada en la ventana produce una lengua común, es atraída por una suerte de propósito esencial hacia allá, y ese allá es menos el destino y más el viaje. En su ser precario ("barro soy...") insiste en el viaje, esa lengua común arrastra en su fuga al ser precario del sujeto, lo hace viajar, le da el viaje, así como él le da espacio en su escritura. Entonces viaje y escritura vienen a ser los dos extremos del agenciamiento y dan lugar a un devenir monarca de la escritura, en tanto la monarca deviene viaje, animal infrahistórico.

En este poema, hay una suerte de fascinación por el poderío de la imagen que se ejerce sobre y desde la subjetividad con el ánimo de exponer lo irrepresentable, así como ocurre con la portada ${ }^{3}$. En este sentido, lo que se dice es también otra cosa, puesto que lo que se mira disimula lo otro que se mira en un mismo objeto. Entonces, el mirar no se presenta como una lejanía que permite acceder al objeto sin comprometer la subjetividad, sino más bien, como la cercanía, mediante la cual la imagen arrastra la subjetividad hacia la palabra en una desaparición siempre actual e infinita del ser, como si el ser del exiliado fuera su desaparición en la materialidad de la imagen y su aparición en el lenguaje. Maurice Blanchot afirma al respecto:

3 Bien podría este libro de Barrientos constituirse en un libro-objeto, en un más allá del tradicional libro de poemas y en cierto modo la poesía del autor entra plenamente en el ámbito de la experimentación. Pero se debiese insistir en lo siguiente: la experimentación poética responde a una circunstancia concreta, el exilio y la necesidad de dar cuenta de ello, a partir de ese exilio y no a un deseo revulsivo o propósito parricida en la perspectiva de lo que se entiende como tradición de la ruptura. Es decir, arrancado de la lengua, el poeta se ve en la necesidad de inventarse una, un idiolecto como señala E. Lihn, a propósito de la lengua de Gabriela Mistral en los libros de su exilio (Tala y Lagar): "El lenguaje de la Mistral es un idiolecto poético que ella forjó en distintas partes del mundo, a partir de la palabra oral recordada y, por así decirlo, de la antiguas escrituras." (Lastra 105). 
La fascinación está fundamentalmente ligada a la presencia neutra, impersonal, el Uno indeterminado, el inmenso Alguien sin rostro. Es la relación que mantiene la mirada -relación neutra e impersonal- con la profundidad sin mirada y sin contorno, la ausencia que se ve porque ciega. (27)

El estado de bloque que anunciábamos en un principio, presenta entonces varios niveles, así como el agenciamiento presente en el texto es una intensificación de un mismo devenir. Primero, un estado de bloque entre narrativa y poética; segundo, un estado de bloque entre la mariposa y la subjetividad básica del texto; tercero, un estado de bloque entre imagen y escritura; y cuarto, un estado de bloque entre viaje y escritura.

En este primer poema, el sujeto exiliado ha tomado al lenguaje por patria. Es decir, se ha instalado fragmentariamente en la intemporalidad del lenguaje, justo allí donde lo que parece afirmarse en el tiempo, se niega en una constante fuga, al extremo de generar una lengua extranjera que ya no refiere al tiempo. Espacio que es un no espacio dominado por la ausencia de tiempo. El otro personaje, la mariposa monarca, le cede el vuelo al sujeto capturado en la espacialidad insatisfactoria del exilio: "yo soy el que vuela y usted la monarca en el baile del celofán." (Barrientos, Monarca 11). Este encuentro impensado ocurre entre el escritor y la mariposa capturada por el artificio del papel celofán, que transfigura la luz. Este diálogo anómalo abre un nuevo escenario. En él, la contaminación de ambos posibilitará profundizar en la condición del exilio, maquinando un artificio, una tecnología arbitraria que permitirá el viaje. Se comprende entonces que la subjetividad básica afirme que "no hay nada que perder, nada que cambiar" (12). Si la pérdida, como esencia, se revela a sí misma en esta espacialidad contradictoria, entonces no hay nada que cambiar, puesto que el exilio es la transfiguración intensificada de lo que es. No hay una intención manifiesta de superar esta condición hacia la tentativa "feliz" de un desexilio. El exilio no se acaba sino que se intensifica. Es la apertura de la subjetividad a la corriente terrible del afuera, es todo él un afuera. Por lo mismo, la subjetividad del exilio está condenada a la repetición infatigable de lo mismo en diversas rutas de intensidad. El versículo final de la tercera estrofa concentra la naturaleza específica de esta escritura marcada por esta presencia intensa: 
Ni caben interpretaciones: estamos hechos a los rasgos

sorpresivos, al aeropuerto anual en donde anida la primera letra. (12)

Se afirma, en definitiva, que el texto enrarecido del exilio está escrito en y con una lengua ajena a la interpretación, que dicha escritura es la misma subjetividad vuelta exilio: "estamos hechos a los rasgos/ sorpresivos, (...)". La figura anómala del exiliado está signada por la indiferencia. En tanto que expulsado, es la disimulación de un "no ser" que se escabulle, el puro rasgo sorpresivo de alguien que "es no siendo" y que "no siendo es" fuera de toda captura y de toda interpretación. El agenciamiento se produce cuando ambos, mariposa y sujeto, comparten esta condición aleatoria e indiferente, ambos están "hechos a los rasgos sorpresivos", ambos están condenados al constante tormento del viaje $\mathrm{y}$, de la misma forma, cercanos a esa zona móvil en donde encuentra origen la escritura: “(...) donde anida la primera letra”. Este más allá del lenguaje, el espacio en donde el lenguaje se dice a sí mismo, es propicio a quienes están fascinados, a quienes están por debajo de la Historia. La relación entre escritura y exilio pasa por este nudo en donde la escritura es un más allá de la escritura y el exilio, el sin lugar, el espacio sin tiempo.

\section{"Mi vida está escrita con tales materias"}

Un primer momento en la escritura de Monarca está marcado por una serie de poemas que figuran la aparición de la subjetividad en la escena de una discursividad opaca y delirante ${ }^{4}$. El agenciamiento guía la discursividad, lo que quiere decir que fruto del encuentro entre la mariposa y la subjetividad básica del texto, se ha producido una subjetividad otra. Esta otra subjetividad la hemos definido como el devenir monarca de la escritura. El primer texto en donde dicha entidad se manifiesta es en el poema “¿A dónde, Ariadna?”. Siendo el devenir el motor que moviliza la escritura, lo que llamaremos el devenir básico del texto tendrá que devenir otra cosa distinta de sí misma.

4 Hablamos de escena en la medida que la escritura sirve de espacio para la aparición de una subjetividad específica, cuya condición está cifrada por la experiencia del exilio. Hablamos de una discursividad opaca en la medida que la expresión de la subjetividad posee rasgos de una cierta irracionalidad o ajena, en todo caso, a los procedimientos típicos del discurso convencional. Hablamos de una discursividad delirante en tanto la expresión procede por el encadenamiento de segmentos contrarios a la lógica de la realidad, entendida desde una perspectiva racional. Aunque dicho carácter delirante no es, en caso alguno, negativo, es el resultado de procesos transfiguradores de la percepción movilizados por la escritura poética. 
El devenir no pertenece a sí mismo, es siempre otra cosa distinta de sí mismo. Por esto, cuando hablamos de una devenir básico, estamos estableciendo un punto cero desde y en el cual se ha hecho evidente un devenir específico a través de una escritura específica. Pero dicho devenir es ya una transfiguración de un estado anterior a la escritura. El devenir monarca de la escritura arrastra en su desplazamiento a la subjetividad hacia un devenir Teseo.

La reescritura del mito griego es un primer momento en el viaje que implica el movimiento de la escritura. Ésta hace delirar a la subjetividad ante la imagen de la metrópolis vista desde arriba. La acumulación de imágenes da cuenta de un laberinto en el cual la subjetividad está perdida. El problema es hacia dónde desplazarse en la naturaleza delirante, residual y fragmentaria de la ciudad. La subjetividad deviene Teseo en tanto ésta enfrenta la imposibilidad de resolver el enigma que cifra la ciudad en su desorden. Esta imposibilidad está dada por la falta de un conocimiento, por la ausencia de un saber, necesario para moverse hacia el espacio en donde es posible superar lo impensado, vencer al Minotauro, que es lo otro. La imagen del Minotauro es la otra cara del laberinto, un mismo ente desordenado, una imagen del caos en cuya escena, Teseo está perdido. Porque al fondo de la escritura del poema, a manera de constatación ontológica, la subjetividad advierte: "Mi vida está escrita con tales materias" (16). Por lo tanto, entendemos que la ciudad agobiante que se ve desde arriba es consustancial a la subjetividad, ésta entiende que su trabajo la enfrenta a sí misma. El viaje entonces es un movimiento en contra de sí. En dicho esfuerzo, la subjetividad intenta liberarse de sí. El devenir Teseo de la subjetividad hace que la monarca devenga Ariadna. El devenir monarca de la escritura es la posibilidad de un conocimiento de lo otro, es la posibilidad de lo impensado. En definitiva, pensarse más allá del mito de sí mismo ${ }^{5}$.

5 Nunca se deviene mayor. Al menos no en la escritura de Barrientos. Devenir mayor implica la congelación del devenir, la captura en una rostridad que impide los movimientos de la subjetividad. En este sentido devenir "Teseo" sería un contrasentido. Sin embargo, la imagen del Héroe aparece oculta en la pregunta y en su lugar aparece Ariadna. La imagen del héroe está disimulada en la pregunta y de esta forma se corrompe la figura de éste situando el conocimiento en el espacio de la escritura, en el artificio, negándole al héroe la presencia heroica, es decir central. Este desplazamiento del centro rompe el relato mítico. La pregunta no es el viaje hacia la confirmación del sí mismo del héroe, la pregunta viene a ser la pregunta por lo otro y de la misma forma es la pregunta por sí mismo. El trabajo consiste más bien en hacer de la imagen del héroe algo distinto de sí. 
Pensamos, por lo tanto, que la producción de la subjetividad se liga a un tipo de saber que se concibe a sí mismo desde y con la escritura en tanto ésta es la posibilidad de transfigurar al sujeto, liberándolo de sí mismo. De esta forma sucede en el poema elegiaco "El oratorio de los cielos reciclamos", en memoria del poeta Humberto Díaz Casanueva ${ }^{6}$. En este poema, los signos que refieren la muerte son transfigurados en otra cosa distinta de la finitud, puesto que la escritura ha operado en la subjetividad una trasformación que le permite una continuidad ontológica más allá de la muerte. La subjetividad se produce entonces por plegamientos en la percepción de la muerte. La estructura elegiaca se transfigura en otra cosa. La muerte es cantada no como signo de la finitud sino como espacio de continuidad, en la medida que la subjetividad entra transfigurada en música. La escritura permite captar el movimiento imperceptible mediante la expresión de signos leves, de presencias livianas que escapan a la percepción ordinaria. Hablamos de un devenir imperceptible de la subjetividad entrando silenciosamente en el espacio de la muerte.

El escritor deviene pianista, mientras que éste deviene piano, se transfigura en piano así como el piano deviene música. Así el escritor, a una velocidad compleja, entra en la dimensión celeste. La zona de la finitud ha sido alterada por la escritura transformándola en un espacio de continuidad. La subjetividad encuentra en la escritura elementos que le permiten transformar ontológicamente la imagen de realidad.

La situación del sujeto no se resuelve en un aislamiento propicio al lamento y la elegía; por el contrario, activa procesos de pensamiento que buscan resolver en el lenguaje una necesidad de encuentro con lo propio y lo otro. De esta forma, da lugar a una voz siempre crítica de procesos colectivos, activos y vitales. Lo paradójico es que la resistencia al exilio se produce desde éste y, particularmente, desde un tipo de pensamiento que, en los bordes últimos de la modernidad, sólo es posible en el exilio, sea éste político-exterior o filosófico-interior. En este plegamiento del lenguaje provocado por el destierro, se da lugar a una lengua siempre extranjera, que nos habla desde un espacio impensado y cuya dificultad de lectura viene a ser la exigencia de descentramiento, necesario a toda escritura marcada por la presencia del exilio.

6 Díaz-Casanueva: 190-191. 
El exilio ha sido esa mecánica que ha trabajado la subjetividad hasta hacerla gravitar en un vacío, en el cual la escritura viene a ser tabla de náufrago, pero el caso es que la escritura, cuando alcanza este status de sobrevivencia, se niega como espacio y adquiere, bajo el signo de una negación significativa, un carácter de vacuidad silenciosa, un no espacio caracterizado por un uso otro de la lengua, una transfiguración de la lengua que supone un sujeto violentado, un ser violentado al extremo de su desaparición, al extremo de mutar el Yo por un él fugaz, efímero ${ }^{7}$.

En Monarca se retoma una línea de deseo, proyectada en Pie del efímero (1985), reorientando los sentidos del viaje a raíz de un nuevo nacimiento. Ese estado embrionario dará lugar a una formación subjetiva de otro signo que problematizará los sentidos del viaje, como si la subjetividad encontrara en la constante fuga una esencia. Esencia no en el sentido de lo que es en función de una verdad a priori, sino que esencia en el sentido de lo que es en su imposibilidad, en su irrepresentabilidad, que es su única posibilidad. En este sentido, Monarca parece encarnar, dar sustancia a una especie de ontología negativa -en la cual la subjetividad es menos sí misma- con la que va dando nombre y voz a fragmentos de subjetividad en un movimiento intenso, que busca agenciar a toda velocidad con multitudes oscuras, con voces que aparecen para volver a perderse; mutando, ocultándose de cualquier requerimiento. En definitiva, la subjetividad en Monarca es a costa de no ser. Es esta la dificultad básica que ofrece la lectura del texto y no la enmarañada constitución del significante, porque los movimientos de la escritura no están orientados, como en Pie del efímero, a la representación de la realidad del sujeto exiliado, sino más bien a la configuración de una subjetividad por múltiples agenciamientos. Es escritura de puro devenir en la cual se producen encuentros impensados, en donde la voz propia del desgarro se encuentra con otras voces del desgarro.

7 Como en el caso del texto de 1985. El artificio necesario es, en ese texto, la construcción de una máquina que opera por desterritorialización, conjugando en un mismo espacio de lenguaje transfigurado los códigos de la poesía y el teatro. Una máquina teatral que permite representar lo irrepresentable, la situación del sujeto exiliado, la subjetividad que, atrapada en un red intensa de no pertenencias, comienza a desaparecer en la luz opaca del lenguaje. Hacia el final de Pie del efímero el sujeto se encoge recostado en el suelo, orientado hacia el sur, es decir hacia el origen: "Y después enrollarnos quietecitos/mirando hacia el sur." (102). En un trabajo anterior decíamos de estos versos que el acto enunciado: “(...) posee a lo menos dos significaciones. La primera: que si bien es posible renunciar al viaje, al imposible retorno, no se puede renunciar al origen que es el nacimiento; la segunda: que este acto de clausura involucra un nuevo nacimiento." (Garrido 40) 


\section{"Temo terriblemente estar repitiendo la historia"}

Un segundo momento en la escritura de Monarca se refiere a una serie de textos que establecen diálogos críticos con el espacio cultural norteamericano. Mediante el uso reiterado de una máquina narrativa, el texto produce una discursividad de carácter infrahistórico, generando una especie de archivo en el cual va disponiendo hechos intrascendentes protagonizados por personajes oscuros de la infracultura norteamericana. Estas "prótesis infrahistóricas" 8 producen en el texto zonas de subjetivación en las que se da espacio a una multiplicidad de voces, verdaderos coros que narran acciones ocurridas en una zona de temporalidad indiferente. En estas zonas de subjetivación, señala Deleuze, "cada cual deviene maestro de su velocidad, relativamente maestro de sus moléculas y de sus singularidades" (Foucault 158). Los personajes alumbrados por la escritura dan cuenta, en su precariedad, de un tipo de saber marginal, en cuyo espacio se actualiza un estado de alienación cultural, similar al experimentado por la subjetividad básica del texto, en tanto ente fragmentario. Los textos en los cuales es posible advertir lo anterior actúan como prótesis que suplen la carencia histórica esencial sobre la que se construye la subjetividad. La falta de un relato en el cual incluirse exige una fabulación por parte del sujeto, que mienta un tipo de ser alterno, una ontología negativa, es decir, un no-ser que sólo es posible por y en el lenguaje. Y lo anterior, en la medida que la lengua es el espacio propicio para este tipo de subjetividad negativa. Con relación a lo anterior, cito del estudio de Elizabeth Collingwood-Selby (1997), Walter Benjamin: la lengua del exilio, el siguiente fragmento:

Ante todo, habría que decir que la lengua, humanamente entendida, no puede más que concebirse como lengua del exilio. Tal afirmación apunta, por una parte, al reconocimiento de la impropiedad de todo lenguaje. Estamos condenados a

8 El artefacto teórico al que nos referimos los hemos construido a partir de una noción extraída del pensamiento de Paul Virilio. El autor francés, en el texto Estética de la desaparición (1998) reflexiona sobre las modificaciones en los órganos perceptores humanos por mecanismos tecnológicos, los cuales suplen carencias, las que se han visto intensificadas por las alteraciones tiempo-espaciales de la modernidad. Virilio construye la noción de "Prótesis técnicas" y da ejemplos de ello como la "fotografía, la pintura de caballete, vehículos rápidos..." (12). Las prótesis son dispositivos mecánicos diseñados para reproducir la forma y/o la función de un miembro (o parte de él) ausente. De acuerdo a lo anterior una prótesis infrahistórica suple la carencia de un relato histórico, pero al reproducir artificialmente dicha carencia deviene "infra", es decir, en un espacio menor con respecto al significante cultural dominante. 
una lengua que jamás nos es propia; y esto no dice: "estamos condenados a hacer uso de una lengua que no nos es propia", sino más bien: "estamos condenados a ser en una lengua que no nos es propia". Somos la lengua en el exilio; somos en lengua extranjera. (136)

El devenir monarca de la escritura arrastra la subjetividad hacia las escenas infrahistóricas que configuran fragmentariamente una punta de desterritorialización: "la embarcación como interior del exterior" (Deleuze, Foucault 158). La escritura se desplaza hacia lo otro, genera mecanismos de disimulación y de enmascaramientos de una subjetividad que busca por diversos medios dar a conocer una situación de agobio existencial. Los textos dan cuenta de un enfrentamiento con la existencia en la forma crítica de una sobrevivencia o subversión, que se traduce en un estado precario amenazado por fuerzas exteriores ligadas al ejercicio brutal del poder, en cualquiera de sus formas modernas9. En este sentido, debemos considerar que la abundante ficcionalización presente en esta escritura está forzada por la realidad, espacio enrarecido, propenso constantemente al colapso de sus significantes culturales básicos. La respuesta de la escritura poética a esta prolongada escena insuficiente y de una paulatina fragmentación, se da en la forma de una narratividad dominada por sujetos agónicos, protagonizada por espectros que ocultan una subjetividad problemática y profundamente crítica de la realidad. Hay una suerte de interiorización del exterior y una posterior exteriorización de la interioridad violentada en la forma de un testimonio indirecto, un modelo a escala de la situación precaria de la realidad.

"Años difíciles" sitúa la narración en el periodo inicial de la crisis del 29 en los Estados Unidos. El texto produce y articula una serie de escenas narradas de forma omnisciente, protagonizadas por sujetos que reflexionan sobre su condición existencial precaria. La aparente objetividad del texto está minada por la aparición intensa de imágenes que coartan la narratividad. De esta forma, la alusión histórica, situada fuera de la esfera de lo histórico dominante, viene a ser un encuentro de precariedades: el devenir monarca de la escritura y las múltiples

9 Entiéndase la maquinaria genocida de la conquista americana, los campos de concentración nazi, las explosiones atómicas que pusieron fin a la Segunda Guerra Mundial, las dictaduras latinoamericanas de la segunda mitad del s. XX. 
presencias que surgen de la fabulación histórica. Así, el texto da voz a los espectros que arroja fuera de sí el gran relato histórico, agencia y produce con ellos un espacio infrahistórico, un exilio-discurso. Esta zona está habitada por "hablantes líricos (...) siempre errantes, se singularizan asimismo por su carácter de sujetos "perdidos y errantes" (Alonso et al. 69). en mundos extraños. Monarca mantiene y reproduce este procedimiento discursivo, es decir, la presencia de enmascaramientos de la subjetividad ${ }^{10}$. Los personajes nombrados en la narración insuficiente no son sino máscaras que el devenir monarca de la escritura provee a la subjetividad básica del texto, con el ánimo de hacer aún más intenso el pensamiento del exilio: "Así, la estructura reflexiva de los textos, desde ya un signo de coincidencia, nos indica que el hablante, a pesar de sus diversos rostros, conserva un status básico: es siempre un sujeto violentado." (Alonso et al. 38). Pero esta violencia no debe ser entendida como negatividad. $\mathrm{Su}$ vitalidad consiste en una resistencia activa, una zona de diálogo desgarrado ${ }^{11}$. Dicho espacio, afirma Gilles Deleuze, "el punto más intenso de las vidas, aquél en el que se concentra su energía, se sitúa allí donde éstas se enfrentan al poder, forcejean con él, intentan utilizar sus fuerzas o escapar a sus trampas" (Deleuze, Foucault 125)

Las múltiples presencias que pueblan los textos de Monarca enmascaran la subjetividad básica del texto, o bien, lo doblan. Son lo otro que el sujeto en su movimiento encuentra en las zonas de la otredad. El doble, como lo entiende Foucault:

\section{(...) es una interiorización del afuera. No es un desdoblamiento de lo Uno, es una repetición de lo Diferente. No es la emanación de un Yo, es la puesta en inmanencia de un siempre otro o de un No-yo. En redoblamiento lo otro nunca es un doble, soy yo el que me vivo como el doble de lo otro: yo no estoy en el exterior, encuentro lo otro en mí ("se trata de mostrar como lo Otro, lo Lejano, también es lo más próximo y lo Mismo"). (Deleuze, Foucault 129)}

10 Esto ya ha sido señalado por Gilberto Triviños en el estudio introductorio a la antología Las Plumas del colibrí. Quince años de poesía en Concepción (1973-1988): “Los personajes poéticos de Pie del Efímero (1985) de Barrientos, paradigma de orquestación de máscaras líricas" (69).

11 Al respecto Gilles Deleuze se interroga “¿Qué nos queda, pues, sino esas vidas anónimas que sólo se manifiestan al enfrentarse con el poder, al forcejear con él, al intercambiar con él "palabras breves y estridentes" antes de regresar a la noche, eso que Foucault llamaba "la vida de los hombres infames", y que proponía a nuestra consideración en razón de "su desgracia, de su rabia o de su dudosa locura?"'" (Foucault 126). 
En este sentido, Monarca redobla los lugares y presencias aludidos minando el mito de la distancia. El exiliado es siempre lo otro, ya lo decíamos, un no-yo. Como en el poema "Esas campanas locas (1932)" en donde la subjetividad se vive a sí misma en la figura de un desempleado que afirma: "Temo terriblemente estar repitiendo la historia" (25), es decir, plegándola, doblándola. O como en el poema "Domingo" en la figura de un fotógrafo que se precipita cámara en mano sobre la ciudad ocupada por desocupados (17).

Estos múltiples devenires son el material con los cuales el texto va generando una suerte de absoluta memoria. El periplo sostenido por la escritura de Barrientos, desde Pie del Efímero (1985) hasta Monarca (1997), lo ha llevado desde el destierro al destiempo. La categoría "destiempo" de Claudio Guillén (1998) establece la condición actual -o posmoderna, si se quiere-, del intelectual, quien parece estar desligado de la temporalidad histórica dominante. "El destierro conduce a ese "destiempo" (...) a ese décalage o desfase en los ritmos históricos de desenvolvimiento que habrá significado, para muchos, el peor de los castigos: la expulsión del presente; y por lo tanto del futuro-lingüístico, cultural, político- del país de origen" (83). Por ello, el exilio-discurso de Barrientos da espacio en esa zona fronteriza (entre un aquí y un allá, entre un pasado y un futuro, entre un antes y un ahora, etc.) a entes ausentes con los cuales mantiene una cercanía vital, la misma ausencia con la cual produce una "vida ausente", según la terminología de Claudio Guillén. La relación que establece el exilio-discurso con la temporalidad es crítica, en la medida que la utiliza, la pliega subjetivándola -"El tiempo como sujeto o como subjetivación", dirá Deleuze-, produce una memoria con el tiempo de la ausencia, pero "no esa corta memoria que viene después, y que se opone al olvido, sino la "absoluta memoria" que dobla el presente, que redobla el afuera, y que se identifica con el olvido, puesto que ella misma es sin fin olvidada para ser rehecha" (1987: 141). Los personajes convocados por la escritura de Barrientos vienen del olvido de la Historia, son infrahistóricos en la medida de su precariedad, y luego de ser expuestos o abiertos por la escritura son devueltos al olvido, que es su pliegue esencial. 


\section{Conclusión}

Tenemos en esta escritura una fuente que ha sido borrada, un "archivo ausente ${ }^{\prime \prime 12}$ desde el cual surgen estas figuras fantasmales, dan testimonio de su ausencia y vuelven a desparecer, tal como la subjetividad básica del texto, cuya condición es la fragmentariedad y la ausencia. Con ellos, el texto crea lo que Ricardo Piglia entiende como "Pueblos de frontera". Estos "se manejan entre dos historias, en dos tiempos y a menudo en dos lenguas. Una cultura nacional dispersa y fracturada, en tensión con una tradición dominante de alta cultura extranjera" (36). Podríamos afirmar que los pueblos de Barrientos son fronterizos, están codificados por múltiples archivos fragmentarios, tensionados por una línea-exilio que los hace ausentes, faltan en la Historia. Entonces, el escritor ha devenido archivista, historiador anómalo, narrador insuficiente, infrahistórico y su discursividad se ha construido y se construye sobre un archivo, deviene prótesis infrahistórica, narratividad insuficiente.

Ricardo Piglia, con relación a la situación específica de su narrativa, ha señalado:

Un historiador es lo más parecido que conozco a un novelista. Los historiadores trabajan con el murmullo de la historia, sus materiales son un tejido de ficciones, de historias privadas, de relatos criminales, de estadísticas y partes de victoria, de testamentos, de informes confidenciales, de cartas secretas, delaciones, documentos apócrifos. La historia es siempre apasionante para un escritor, no sólo por los elementos anecdóticos, las historias que circulan, la lucha de interpretaciones, sino porque también se pueden encontrar multitud de formas narrativas y modos de narrar. (98)

En el caso de la escritura de Monarca, constatamos la presencia de un devenir historiador, pero de un tipo infra. La intencionalidad narrativa, decíamos al principio de este capítulo, al entrar en contacto con la escritura poética, se imposibilita. Por lo tanto, transfigura el

12 La existencia de un archivo previo a la escritura nos parece fundamental en lo que se refiere a la escritura de Monarca. Este concepto lo estamos tomando (y lo modificamos) del pensamiento de Ricardo Piglia, quien afirma: “(...) el archivo como modelo de relato, la tensión entre materiales diferentes que conviven anudados por un centro que justamente es lo que hay que construir. (...) por supuesto que los historiadores trabajan siempre con la ficción y la historia es la proliferación de mundos posibles." (98). 
devenir historiador o narrador, siguiendo el pensamiento de Piglia, en una imagen anómala y disfuncional. Dicha figura se instala en otro lugar, en la espacialidad insatisfactoria del exilio, en la cual el discurso deviene "prótesis infrahistórica", porque suple una carencia, pero nunca entrega una solución. El relato es un exilio-discurso, la escritura de una vida ausente que encuentra en su desplazamiento entes ausentes y de la ausencia, grupos menores que hacen devenir la escritura. Como señala Gilles Deleuze:

Se diría que la escritura por sí misma, cuando no es oficial, se encuentra con "minorías", que ni escriben necesariamente por su cuenta, ni tampoco se escribe sobre ellas, en el sentido de que no son tomadas como objetos, pero en las que como contrapartida uno está atrapado, quiérase o no, por el hecho de escribir. (Diálogos 52)

Lo señalado por Deleuze se relaciona directamente con la escritura de Monarca, puesto que los entes ausentes que agencian en su escritura comparten con él ese estado de ausencia propio de la marca del exilio.

La intensidad esencial de la escritura de Monarca se relaciona con un desplazamiento vital que rompe la marca inicial del exilio. Ya no se trata de una interiorización del destierro como dimensión Histórica, singular e individual, sino de una apertura del exilio-discurso hacia lo otro. La textualidad de Monarca está expuesta al afuera posibilitando encuentros impensados de profunda vitalidad: "Al escribir se proporciona escritura a los que no la tienen, y estos a su vez proporcionan a la escritura un devenir sin el cual no existiría" (Deleuze et al., Diálogos 53). 


\section{Bibliografía}

Alonso, Nieves et al. Las plumas del Colibrí. Santiago de Chile: Ed. Improde/Cesoc., 1989.

Barrientos, Raúl. Pie del Efímero. Concepción, Chile: Editorial El Maitén, 1985.

Monarca. Canadá: Editorial Cordillera, 1997.

Blanchot, Maurice. El espacio Literario. Buenos Aires: Editorial Paidós, 1969.

Collingwood-Selby, Elizabeth. Walter Benjamin: la lengua del exilio. Santiago de Chile: LOM, Escuela de Filosofía Universidad ARCIS, 1997.

Deleuze,Gilles, et al. Diálogos. Valencia: Editorial Pre-textos, 1997.

Deleuze, Gilles. Foucault. Buenos Aires: Editorial Pre-textos, 1987.

Díaz-Casanueva, Humberto. "La poesía de Raúl Barrientos” en Revista Araucaria de Chile 21 (1983): pp. 190-191

Foucault, Michel. De lenguaje y literatura. Barcelona: Editorial Paidós, 1996.

. El pensamiento del afuera. Valencia: Editorial Pre-textos 2000.

Garrido, Marcelo. “Una poética del exilio (tres supuestos de lectura) en Pie del

Efímero de Raúl Barrientos". Tesis para optar al grado de Licenciado en Educación

con mención en español. Universidad de Concepción, Concepción, 2001.

Lastra, Pedro. Conversaciones con Enrique Lihn. Santiago de Chile: Editorial Universitaria, 2009.

Guillén, Claudio. Múltiples Moradas. Barcelona: Editorial TusQuets, 1998.

Piglia, Ricardo. Crítica y ficción. Buenos Aires: Editorial Seix Barral, 2000.

Virilio, Paul. Estética de la desaparición. Barcelona: Editorial Anagrama, 1998. 